\title{
EXPERIMENTAL AND PERFORMANCE ANALYSIS OF SINGLE NOZZLE JET PUMP WITH VARIOUS MIXING TUBES
}

\author{
Santhosh Kumar Gugulothu ${ }^{1}$ and Shalini Manchikatla ${ }^{2}$ \\ ${ }^{1}$ Department of Mechanical Engineering, Gitam University, Hyderabad, India \\ ${ }^{2}$ Department of Mechanical Engineering, Gitam University, Hyderabad, India
}

\begin{abstract}
Water is central to survival, without water human, plant and animal life would be impossible. Therefore supply of water has become one of the fundamental requirements of any society and the need to transfer water has generated the design of various forms of mechanical devices, which can be categorized as pumps. Jet pump is a device that performs its pumping action by the transfer of energy from a high velocity supply jet to one of low velocity suction flow. These two flows mix in the mixing tube and the kinetic energy of the combined flow is converted partially into the pressure energy in the diffuser. The optimization of the design of single hole nozzle jet pump with various area ratios and five different diameter mixing tubes. For each of the mixing tube, experiments were conducted for two more distances above and the one used for the first set of experiments. The spacing was increased using $2(6 \mathrm{~mm})$ gaskets for one distance and $3(9 \mathrm{~mm})$ gaskets for another distance. The area ratios chosen have been modified and the final area ratios used were $R=0.20,0.28,0.36,0.43 \& 0.50$. Discharge ratios $(M)$, Head ratio $(N)$, Efficiency $(\eta)$ were used to draw performance curves. Experiments were done for all other area ratios as spacing is increasing there is an increase in efficiency.
\end{abstract}

\section{Keywords}

Area ratios, Mixing tube, Multi hole nozzle, Nozzle plates.

\section{INTRODUCTION}

The basic principle of jet pump is the transfer of energy and momentum from one stream of fluid to another through a process of turbulent mixing inside the mixing tube.

The high pressure primary driving stream enters the suction chamber through nozzle with a high velocity. The increase of velocity and the resulting reduction in pressure at the nozzle exit causes the secondary driven fluid to flow into the mixing chamber.

In the mixing chamber the transfer of momentum from the supply stream to secondary stream takes place. The mixed fluid then passes through the diffuser in which a portion of velocity energy is converted into pressure energy.

\subsection{PERFORMANCE PARAMETERS}

The performance of a jet pump depends on turbulent mixing of supply and suction fluids. The mixing process and hence the performance of the jet pump is largely influenced by the following geometric parameters.

DOI : 10.14810/ijmech.2014.3411 
1. Area ratio $(\mathrm{R})$

2.Distance between the nozzle exit and mixing tube entry (S)

3. Mixing tube length $\left(\mathrm{D}_{\mathrm{L}}\right)$

4.Primary nozzle geometry

5. Suction nozzle geometry

6.Diffuser geometry

7.Number and arrangement of holes in the nozzle.

The working of the jet pump depends on the efficient turbulent mixing. At the entry to the mixing tube the velocity of the primary stream and the velocity of the secondary stream are different and non-uniform. The mixing tube will play the role of eliminating or at least minimizing the difference in velocity and the non-uniform distribution before the combined flow leaves the mixing tube. The length of mixing tube and its diameter decide the effectiveness of the mixing tube. These dimensions have a direct bearing on the performance of the jet pump.

The mixing is very effective at high velocities. This is achieved by a smaller mixing tube diameter. This velocity energy is being converted to pressure energy to reduce the loss of energy during subsequent flow i.e. in the diffuser which is located at the exit of the mixing tube. The velocity distribution at the mixing tube entry depends on the primary nozzle and secondary nozzle geometry. All these parameters are having an influence on the jet pump performance.

\subsection{DEFINITION OF VARIOUS TERMS}

The following parameters have been used extensively for describing the jet pump characteristics since they were first suggested by Gosline and O'Brien [1934].

Area ratio (R)

It is the ratio of primary nozzle area to mixing tube throat area and is given by

$$
R=\frac{A_{n}}{A_{m}}=\left(\frac{d_{n}}{d_{m}}\right)^{2}
$$

Where $A_{n}=$ driving nozzle area

$\mathrm{d}_{\mathrm{n}}=$ driving nozzle exit diameter

$\mathrm{A}_{\mathrm{m}}=$ mixing tube throat area

$\mathrm{d}_{\mathrm{m}}=$ mixing tube throat diameter

\section{Discharge ratio (M)}

It is the ratio between suction flow rate and primary flow rate of jet pump.

$$
M=\frac{Q_{2}}{Q_{1}}
$$

Where $\mathrm{Q}_{1}$-Primary flow rate in $\mathrm{m}^{3} / \mathrm{s}$ $\mathrm{Q}_{2}$-Suction flow rate in $\mathrm{m}^{3} / \mathrm{s}$

\section{Head Ratio (N)}

It is the ratio between net jet pump head and net driving head of the jet pump.

Jet pump supply head $\mathrm{H}_{1}$ is given by

$$
H_{1}=\frac{p_{1}}{\gamma}+\frac{v_{1}^{2}}{2 g}+z_{1}
$$


Where

$\mathrm{P}_{1}=$ Supply pressure, $\mathrm{Pa}$

$\mathrm{Z}_{1}=$ Level difference between pressure gauge and pressure tapping $=1.15 \mathrm{~m}$

$v_{1}=\frac{Q_{1}}{A_{1}}$

$\mathrm{Q}_{1}=$ Supply Discharge, $\mathrm{m}^{3} / \mathrm{s}$

$\mathrm{A}_{1}=$ Cross sectional area of supply pipe, $\mathrm{m}^{2}\left(\mathrm{D}_{1}=0.053 \mathrm{~m}\right)$

$\mathrm{g}=$ Acceleration due to gravity, $\mathrm{m} / \mathrm{s}^{2}$

Jet pump suction head $\mathrm{H}_{2}$ is given by

$H_{2}=\frac{p_{2}}{\gamma}+\frac{v_{2}^{2}}{2 g}+z_{2}$

Where

$\mathrm{P}_{2}=$ Suction pressure, $\mathrm{Pa}$

$\mathrm{Z}_{2}=$ Level difference between pressure gauge and pressure tapping $=0$

$\mathrm{Q}_{2}=$ Suction Discharge, $\mathrm{m}^{3} / \mathrm{s}$

$\mathrm{A}_{2}=$ Cross sectional area of Suction pipe, $\mathrm{m}^{2}\left(\mathrm{D}_{2}=0.053 \mathrm{~m}\right)$

$\mathrm{g}=$ Acceleration due to gravity, $\mathrm{m} / \mathrm{s}^{2}$

Jet pump delivery head $\mathrm{H}_{3}$ is given by

$H_{3}=\frac{p_{3}}{\gamma}+\frac{v_{3}^{2}}{2 g}+z_{3}$

Where

$\mathrm{P}_{3}=$ Delivery pressure, $\mathrm{Pa}$

$\mathrm{Z}_{3}=$ Level difference between pressure gauge and pressure tapping $=0$

$\mathrm{Q}_{3}=$ Delivery Discharge, $\mathrm{m}^{3} / \mathrm{s}$

$\mathrm{A}_{3}=$ Cross sectional area of Delivery pipe, $\mathrm{m}^{2}\left(\mathrm{D}_{3}=0.069 \mathrm{~m}\right)$

$\mathrm{g}=$ Acceleration due to gravity, $\mathrm{m} / \mathrm{s}^{2}$

Jet pump head ratio $\mathrm{N}$ is given by

$N=\frac{H_{3}-H_{2}}{H_{1}-H_{3}}$

\section{Efficiency of jet pump $(\eta)$}

It is defined as the ratio of energy increase of suction stream (output energy) to the energy decrease of driving stream (input energy).

$\eta=\left(\frac{Q_{2}}{Q_{1}}\right) \times\left(\frac{H_{3}-H_{2}}{H_{1}-H_{3}}\right)$

Therefore, Jet pump efficiency $\eta$ is given by

$\eta=\mathrm{M} \mathrm{X} \mathrm{N}$

\subsection{JET PUMP ANALYSIS}

The performance of any machine can be predicted by means of theoretical investigations with proper assumptions, which will make the mathematical treatment of the analysis easy. These theoretical investigations may not predict the behavior truly along the complete course of action because of some assumptions but it estimates the effectiveness of the machine up to the required accuracy needed for design purposes. 


\section{PERFORMANCE CHARACTERISTICS}

The performance of a jet pump is graphically represented by

a. Head ratio $(\mathrm{N})$ as a function of Discharge ratio $(\mathrm{M})$

b. Efficiency $(\eta)$ as a function of Discharge ratio $(M)$

The graphical representation of the efficiency and head ratio w.r.t. the discharge ratio is called the performance characteristics of the jet pump. The slope of the head ratio vs discharge ratio curve depends on the area ratio of the jet pump. In case of efficiency vs discharge ratio, the efficiency curve increases till a maximum and then it decreases.

\subsection{MIXING TUBE DESIGN}

The jet pump assembly available in the hydroturbomachines laboratory has facilities to change the various components of the jet pump. Different area ratios have to be achieved since it is the parameter of interest in this project work. Effect of change of area ratio on jet pump performance is to be obtained experimentally using different diameter mixing tubes. The design of mixing tube should match with the existing suction nozzle and diffuser. The procedure of finalizing the dimensions of the suction nozzle, mixing tube and diffuser is discussed in detail in the following sections.

\subsection{EXISTING JET PUMP DETAILS}

The major dimensions of the existing jet pump for an area ratio of 0.282 are

$\begin{array}{ll}\text { Primary nozzle diameter }\left(\mathrm{d}_{\mathrm{n}}\right) & =17 \mathrm{~mm} \\ \text { Mixing tube diameter }\left(\mathrm{d}_{\mathrm{m}}\right) & =32 \mathrm{~mm} \\ \text { Mixing tube length }\left(\mathrm{l}_{\mathrm{m}}\right) & =140 \mathrm{~mm} \\ \text { Diffuser length }\left(1_{\mathrm{d}}\right) & =210 \mathrm{~mm} \\ \text { Diffuser angle }(\beta) & =10^{\circ} \\ \text { Suction nozzle angle } & =50^{\circ}\end{array}$

Spacing between the primary nozzle exit and the mixing tube entrance $\mathrm{S}=17 \mathrm{~mm}$

This jet pump was kept as reference. It was decided to use 5 different area ratios from 0.200 to 0.502 .

\subsection{DESIGN CONSIDERATIONS}

The dimensions of the existing jet pump assembly were kept in view during the design of new components. For each of the area ratio, different parameters like diameter and length of mixing tube, length of diffuser and the spacing between the primary nozzle exit to mixing tube entrance were calculated.

In the study of the effect of area ratio on the performance of jet pump, the annular area available between suction and primary nozzle should be the same for each of area ratio. To fulfill this criterion, a proper spacing between the nozzle exit to the mixing tube entrance to be found out. Table 1 shows the design dimensions for all the chosen area ratios. It may be noted that for these carry, mixing tube length and diffuser length are varying. When expressed non dimensionally mixing tube length as a ratio of mixing tube diameter from smaller area ratio $(\mathrm{R}<0.20)$ pump requires optimum mixing length of 7 to 10 times the diameter. For higher area ratio $(R=0.200$ to 0.502) pumps, mixing tube length of 3 to 5 times the diameter may be sufficient. In this present work ' $l_{\mathrm{m}}$ ' is taken as $4.5 \mathrm{~d}_{\mathrm{m}}$ (approximately). 
This results in $l_{\mathrm{d}} / l_{\mathrm{m}}$ also varying as different mixing tubes used. The selection of diffuser cone angle $(\beta)$ was based on the work of Mueller (1964) who concluded that a diffuser angle of $10^{\circ}$ yields the best efficiency. In this present work ' $\beta$ ' is taken as $10^{\circ}$ and length of diffuser is calculated using diffuser cone angle, mixing tube diameter $\&$ delivery pipe diameter.

Table 1 Finalized dimensions for different area ratios

\begin{tabular}{|c|c|c|c|c|c|c|c|}
\hline $\begin{array}{l}\text { Diameter } \\
\text { of } \\
\text { Primary } \\
\text { nozzle } \\
\left(d_{n}\right) m m\end{array}$ & $\begin{array}{l}\text { Diameter } \\
\text { of } \\
\text { Mixing } \\
\text { tube } \\
\left(d_{\mathrm{m}}\right) \mathrm{mm}\end{array}$ & $\begin{array}{l}\text { Area } \\
\text { Ratio } \\
(\mathrm{R})\end{array}$ & $\begin{array}{l}\text { Spacing between } \\
\text { the primary } \\
\text { nozzle exit to } \\
\text { the mixing tube } \\
\text { entrance (S)mm }\end{array}$ & $\begin{array}{l}\text { Length of } \\
\text { Mixing tube } \\
\left(1_{\mathrm{m}}\right) \mathrm{mm}\end{array}$ & $\begin{array}{l}\text { Length of } \\
\text { Diffuser } \\
\left(1_{d}\right) \mathrm{mm}\end{array}$ & $\mathrm{l}_{\mathrm{m}} / \mathrm{d}_{\mathrm{m}}$ & $1_{d} / d_{m}$ \\
\hline 17 & 38.0 & 0.200 & 10.20 & 170.0 & 173.0 & 4.47 & 4.55 \\
\hline 17 & 32.0 & 0.282 & 17.00 & 140.0 & 207.7 & 4.37 & 6.56 \\
\hline 17 & 28.2 & 0.363 & 21.25 & 129.5 & 229.0 & 4.59 & 8.12 \\
\hline 17 & 25.9 & 0.431 & 23.80 & 120.0 & 242.0 & 4.63 & 9.34 \\
\hline 17 & 24.0 & 0.502 & 25.50 & 110.0 & 253.0 & 4.58 & 10.54 \\
\hline
\end{tabular}

\section{TEST SETUP AND EXPERIMENTATION}

\subsection{DESCRIPTION OF THE TEST SETUP}

The schematic layout of the setup showing the connecting lines along with the centrifugal pump is given in Fig.1. The test setup was designed to determine the jet pump performance. The setup has provision to measure the pressure and discharge at various points of the system.

The test setup mainly consists of three subsystems.

1. Jet pump assembly and its pipelines

2. A centrifugal pump and its pipelines

3. Instrumentation

Centrifugal pump is used to provide the required supply to the primary nozzle of the jet pump. The delivery line of the centrifugal pump is connected to the primary nozzle through a valve V1 shown in Fig.1. There is a sliding joint at the jet pump delivery line permitting the change of either nozzle or mixing tube or diffuser without disturbing the pipeline.

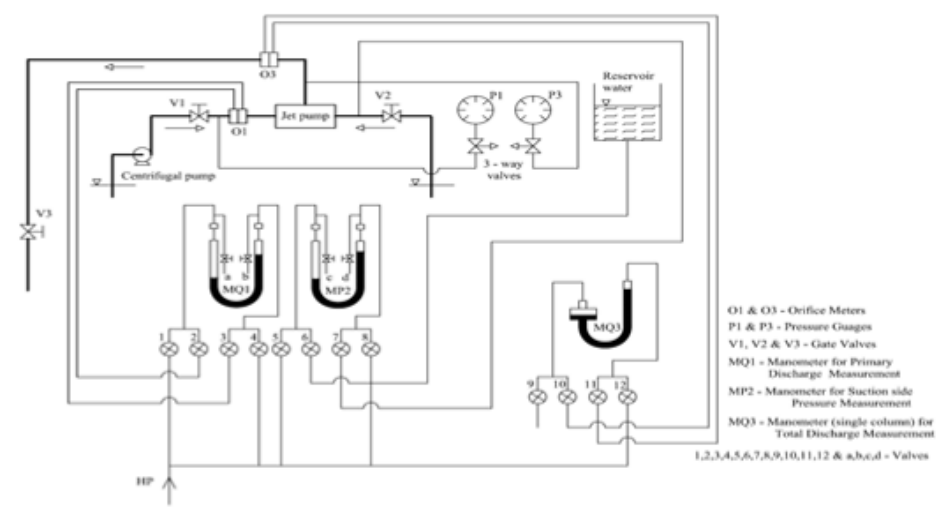

Figure1. Layout \& Measuring arrangement of the test setup 
Jet pump pipeline is provided with control elements mainly consisting of

1. Delivery valve V3 which is used to control the delivery pressure of the jet pump

2. A suction valve V1 which can be used to vary the suction pressure of the pump

This control arrangement is used to obtain the non-cavitation and cavitation characteristics of the jet pump respectively.

\subsection{SETUP SPECIFICATIONS}

The supply pipe and suction pipe diameter are $53 \mathrm{~mm}$ (2"). The delivery pipe diameter is $69 \mathrm{~mm}$ (2.5”). The design specifications of centrifugal pump has been given as $\mathrm{H}=15.4 \mathrm{~m} \mathrm{\&} \mathrm{Q}=0.004$ $\mathrm{m}^{3} / \mathrm{s}$. The energy supplied to the jet pump can be obtained by subtracting the frictional losses in the pipelines and the level difference.

\subsection{INSTRUMENTATION}

\subsubsection{Discharge Measurement}

The discharge at the supply and delivery sides of the jet pump was measured by two orifice meters of diameters $22 \mathrm{~mm}$ and $38 \mathrm{~mm}$ respectively. The discharges were calculated using the formula

$Q=C_{d} \times a \times \sqrt{2 g \Delta h}$

Where

$\mathrm{Q}=$ Discharge in $\mathrm{m}^{3} / \mathrm{s}$

$C_{d}=$ Coefficient of discharge of the orifice meter

$\mathrm{a}=$ Cross sectional area of orifice, $\mathrm{m}^{2}$

$\mathrm{g}=$ Acceleration due to gravity, $9.81 \mathrm{~m} / \mathrm{s}^{2}$

$\Delta h=$ Pressure difference across the orifice meter, $\mathrm{m}$ of water

The coefficients of discharge were calculated according to IS 2952 Part I-(1964). The calculated coefficient of discharge values for $22 \mathrm{~mm}$ and $38 \mathrm{~mm}$ diameter orifice meters were 0.613 and 0.642 respectively. The suction side discharge was calculated from delivery side discharge $\left(\mathrm{QBBB}_{3}\right)$ and supply side discharge $\left(\mathrm{QBBB} 11_{1}\right)$ using continuity equation

$$
\mathrm{Q}_{2}=\mathrm{Q}_{3}-\mathrm{Q}_{1}
$$

\subsubsection{Static Pressure Measurement}

Piezo-rings were provided at suction, supply and delivery side of the jet pump to obtain the average pressure at those points.

The static pressure at supply side $\left(\mathrm{P}_{1}\right)$ and delivery side $\left(\mathrm{P}_{3}\right)$ of the jet pump were measured by calibrated pressure gauges of range 0 to $2.5 \mathrm{~Pa}$ and -1.0 to $1.0 \mathrm{~Pa}$ respectively. A U- tube mercury

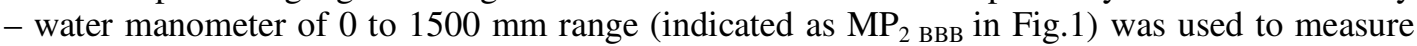
the pressure at the suction side $\left(\mathrm{P}_{2}\right)$ of the jet pump. The other limb of this manometer was connected to a reservoir with water level at the center of the pressure gauges. 


\section{EXPERIMENTAL PROCEDURE}

\subsection{Venting and Measuring Arrangements}

Before starting the experiment, the control valve V1 (Supply pipe control Valve), V2 (suction pipe control valve) and V3 (Discharge pipe Control Valve) should be kept in full closed position. The centrifugal pump motor was started to supply the water to supply pipe which was connected to the primary nozzle. Then all the valves were opened fully. Before taking readings, venting should be done for all pressure lines, manometers and pressure gauges. For this purpose, the pressure line connections are arranged as shown in Fig. 1 . The venting can be done by opening some of the valves as indicated in Table 2. This table shows the valves which are to be kept in open position and remaining valves are kept in closed position when performing the listed task.

Two 3-way valves were used in measuring $\mathrm{PBB}_{1 \mathrm{Bв}}$ and $\mathrm{PBB}_{3 \mathrm{BB}}$ (Supply and Delivery Pressures). The four possibilities of 3-way valve configurations are shown in Fig 2. For venting, the 3-way valves were kept at position $-1 \&$ they were kept at position -2 for measuring. Three way valve can be used in position -3 for venting of measuring line and in position - 4 for measuring of atmospheric pressure.

\subsection{Performance Tests}

Once venting is completed, readings were taken to determine the performance of jet pump. It should be ensured that the valves 2, 3, 6, 7, 10 and 11 should be kept open and 3-way valves in position 2 when readings are being taken.

Several sets of experiments are performed on the setup by varying the diameter of the mixing tube and gasket

In the observation table, the supply discharge readings in U-tube mercury - water manometer, the delivery discharge readings in single column mercury - water manometer, the supply and delivery side static pressures from pressure gauges $\mathrm{P}_{1 \text { ввв }}$ and $\mathrm{P}_{3 \text { ввв }}$, and the suction side pressure reading in $\mathrm{U}$ tube mercury - water manometer were noted .

After taking the first set of readings with V1, V2, and V3 in full open position, the delivery valve V3 was partly closed keeping primary valve V1 and suction valve V2 in full open position. For various discharge valve (V3) openings, the readings were noted.

From the observed readings, supply discharge (Q1), Delivery discharge (Q3), Supply side static pressure $\left(\mathrm{PB} 1 \mathrm{BB}_{\mathrm{BBB}}\right)$, Delivery side static pressure $(\mathrm{P} 3)$, Suction side static pressure $\left(\mathrm{PB} 2 \mathrm{BB}_{\mathrm{BBB}}\right)$, from the reading head calculated. From these values discharge ratio $(M)$, Head ratio $(N)$, efficiency $(\eta)$ were found out and the performance curves of the jet pump were plotted.

Table 2 Valve positions for venting \& measurement

\begin{tabular}{|l|l|l|l|l|l|}
\hline \multicolumn{5}{|c|}{ Venting } & \multirow{2}{*}{ Measuring } \\
\hline & Pressure Connections & Manometers & \\
\cline { 2 - 6 } & Positive side & Negative side & Positive side & Negative side & \\
\hline MQ1 & 1,2 & 3,4 & 1, a & 4, b & 2,3 \\
\hline MQ2 & 5,6 & 7,8 & 5, c & 8, d & 6,7 \\
\hline MQ3 & 9,10 & 9,11 & 9,12 & 9,12 & 10,11 \\
\hline P1 & Position 1 & ----------- & ---------- & ----------- & Position 2 \\
\hline P2 & Position 1 & ---------- & ---------- & ---------- & Position 2 \\
\hline
\end{tabular}




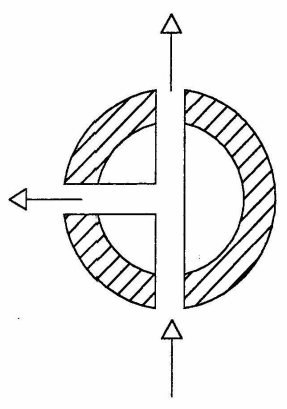

position 1

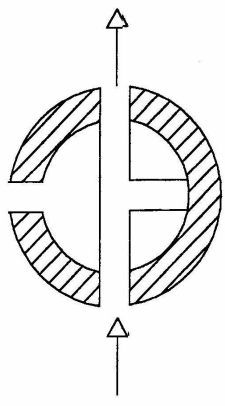

position 2

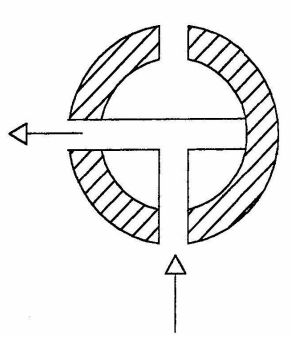

position 3

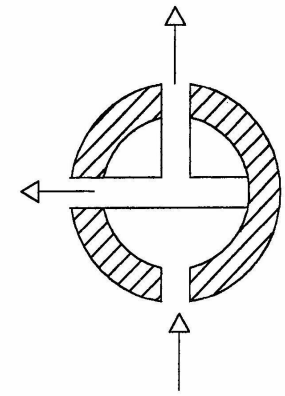

position 4

Figure 2. Positions of 3-way valve

\section{EFFECT OF CHANGE OF ' $S$ '}

For each of the mixing tube, experiments were conducted for two more distances above and the one used for the first set of experiments. The spacing was increased using $2(6 \mathrm{~mm})$ gaskets for one distance and $3(9 \mathrm{~mm})$ gaskets for another distance.

Table 3 gives the summery of mixing tube diameter $d_{m}$, area ratio nozzle to mixing tube spacing $S$ and the corresponding number of the figure.

In fig. $4 \& 5$ shows the results for an area ratio of 0.200 at spacing (S) of $13.20 \mathrm{~mm} \& 16.20 \mathrm{~mm}$. Here as distance is increasing between the primary nozzle exit to mixing tube entrance, the performance characteristic of jet pump shows that the efficiency increases as the spacing is increased. Because the head ratio maximum at $0.33 \& 0.31$, discharge ratio is zero. The operating ranges of discharge ratio were from 0.3 to $0.63 \&$ from 0.2 to 0.72 . The range of head ratio obtained were from 0.3 to 0.17 and from 0.28 to 0.17 with on the range of experimental results only an increase in efficiency was noted as discharge ratio was increased.

A study of the results obtained at other area ratios indicated that the operating range is more or less the same possibility due to the limitation in the setup. At higher area ratios the efficiency curves showed a defined point of maximum efficiency. There was also a variation of maximum efficiency for a given area ratio as the spacing was increased.

Table 3 Details of spacing between nozzle to mixing tube and figures

\begin{tabular}{|l|l|l|l|}
\hline $\begin{array}{l}\text { Mixing tube diameter }\left(\mathrm{d}_{\mathrm{m}}\right) \\
\mathrm{mm}\end{array}$ & Area Ratio R & $\begin{array}{l}\text { Spacing between nozzle to } \\
\text { mixing tube }(\mathrm{S}) \mathrm{mm}\end{array}$ & Figure number \\
\hline 38.0 & 0.200 & 10.20 & 3 \\
& & 13.20 & 4 \\
32.0 & 0.282 & 16.20 & 5 \\
\hline & & 2.00 & 6 \\
& 23.00 & 7 \\
\hline
\end{tabular}




\begin{tabular}{|l|l|l|l|}
\hline 28.2 & & 21.25 & 9 \\
& 0.363 & 24.25 & 10 \\
\hline \multirow{2}{*}{25.9} & & 27.25 & 11 \\
\hline & 0.431 & 23.80 & 12 \\
& & 26.80 & 13 \\
\hline \multirow{2}{*}{24.0} & & 29.80 & 14 \\
& \multirow{2}{*}{0.502} & 25.50 & 15 \\
& & 28.50 & 16 \\
\hline
\end{tabular}

\section{RESULTS AND DISCUSSIONS}

Experimental results were obtained with water (water to water) as the working fluid.

\subsection{PERFORMANCE CHARACTERISTICS}

The Discharge Ratio (M), Head Ratio (N), and Efficiency $(\eta)$ were used to draw the performance curves.

The experiment was conducted first with the existing jet pump of area ratio 0.282. Same experiment was done again to check the repeatability.

Experiments were done for all other area ratios and specifications as given in the Table1 and the characteristics of the jet pump were determined. It may be mentioned here that a simple gasket of $3 \mathrm{~mm}$ was used while fixing the mixing tube in order to obtain the spacing between primary nozzle exits to mixing tube entrances indicated in Table1. The performance characteristic curves for jet pump of area ratio $(\mathrm{R})=0.200,0.282,0.363,0.431,0.502$ are given in the Fig. 3 to 17 . In these figures, results of two trials are shown. It may be seen that the repeatability of experimental results is good. In this plot M-N curves are fitted as a straight line by the method of least squares. Efficiency of the jet pump is the product of $\mathrm{M}$ and $\mathrm{N}$. Hence values of $\mathrm{M}$ and $\mathrm{N}$ are calculated from the fitted curve M-N. Efficiency generally increases with discharge ratio up to a maximum and then it decreases. If Fig. 3 is considered it may be observed that the range of discharge ratio is from 0.2 to 0.63 and head ratio is from 0.15 to 0.33 .

As the area ratio is increased further, it may be observed that the head ratio at discharge ratio is equal to 0 increases to expect for the area ratios of $0.597 \& 0.723$. The range of discharge ratio for which readings could be obtained was between 0.15 and 0.7 in most of the cases due to the limitations of the test rig.

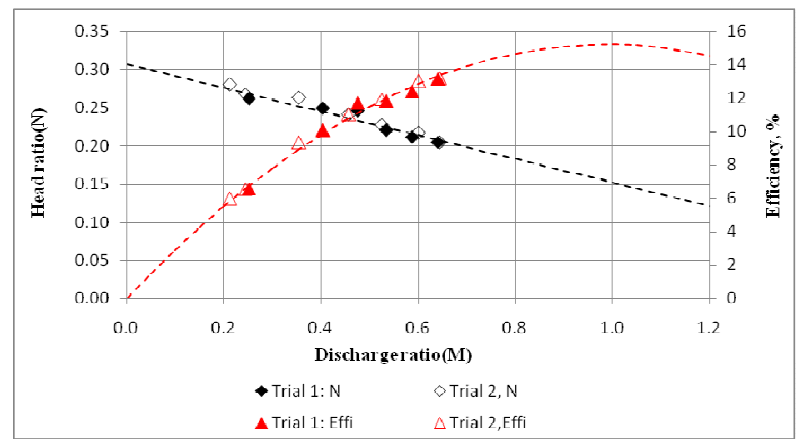

Figure 3. Performance characteristics of jet pump with $\mathrm{R}=0.200 \& \mathrm{~S}=10.20 \mathrm{~mm}$ 


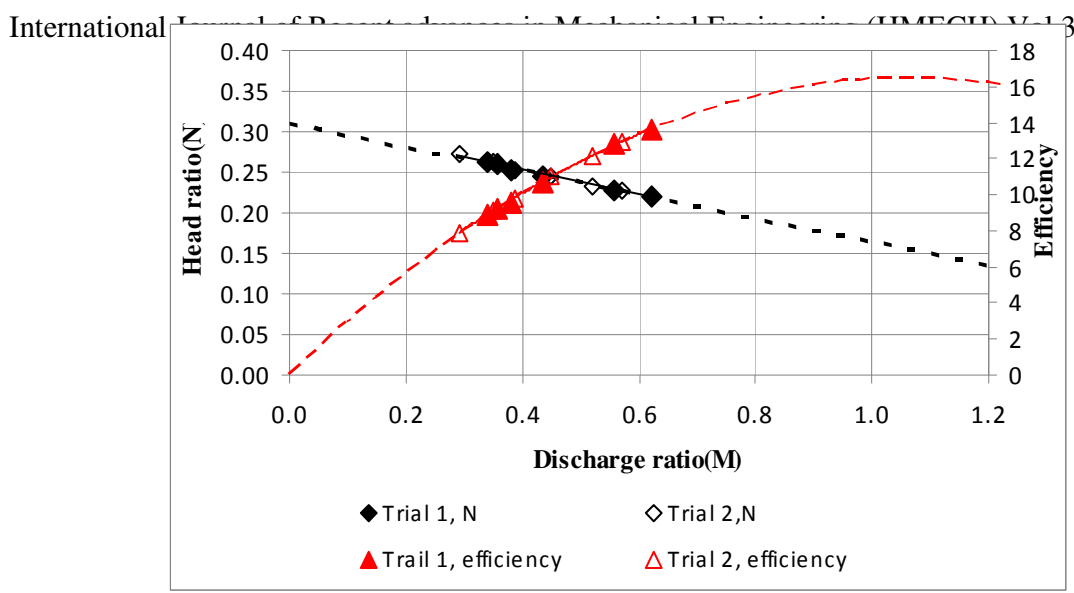

Figure4. Performance characteristics of jet pump with $\mathrm{R}=0.200 \& \mathrm{~S}=13.20 \mathrm{~mm}$

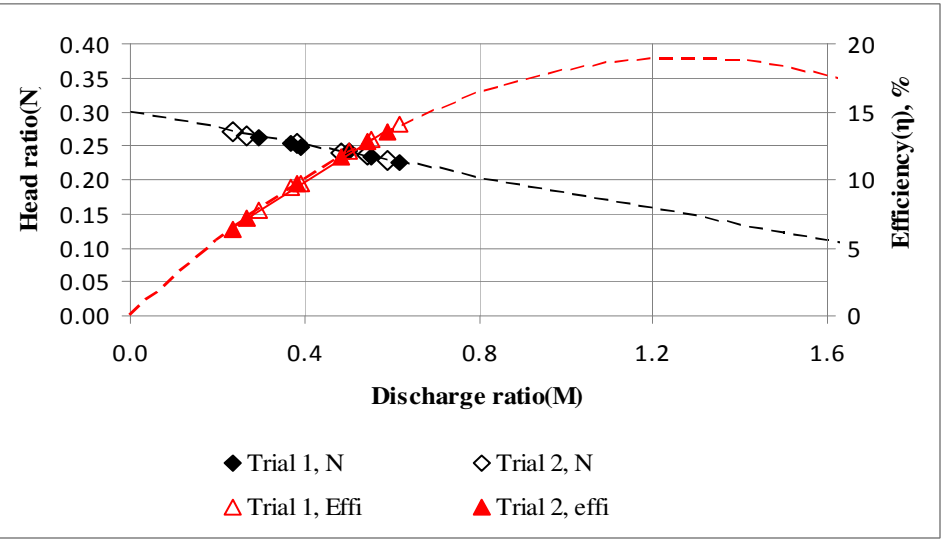

Figure5. Performance characteristics of jet pump with $R=0.200 \& S=16.20 \mathrm{~mm}$

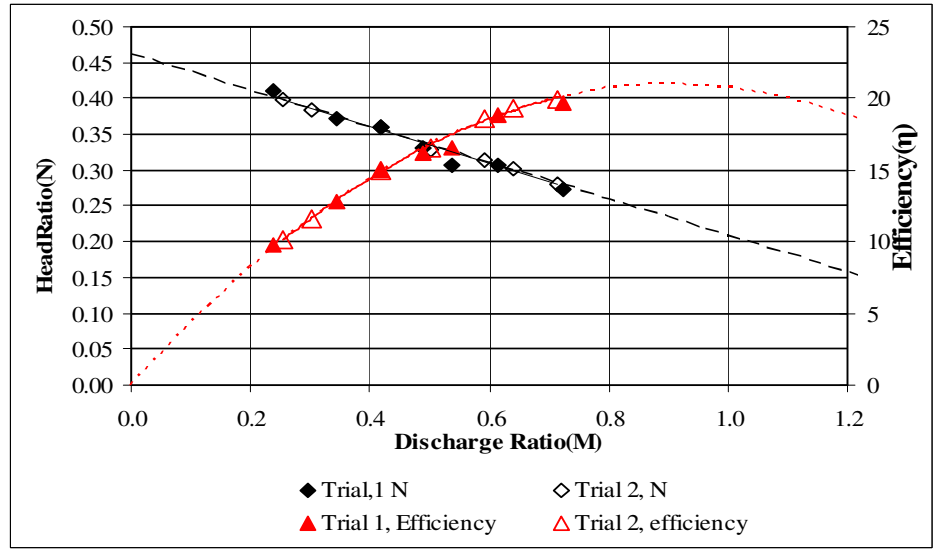

Figure6. Performance characteristics of jet pump with $\mathrm{R}=0.282 \& \mathrm{~S}=17.00 \mathrm{~mm}$ 


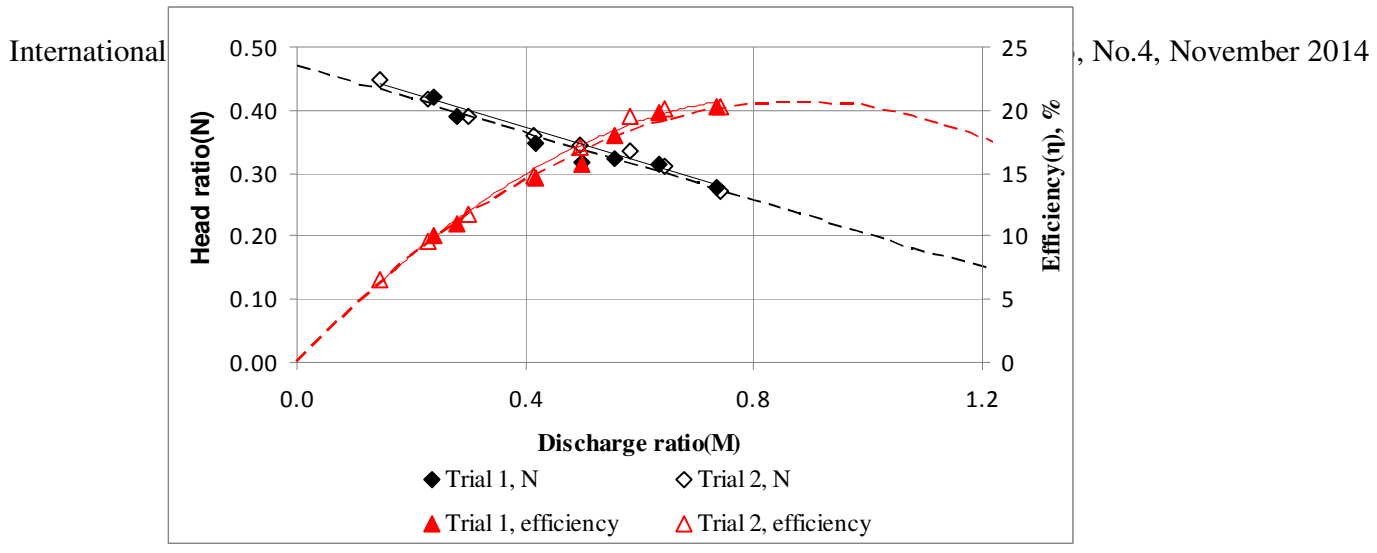

Figure7. Performance characteristics of jet pump with $R=0.282 \& S=20 \mathrm{~mm}$

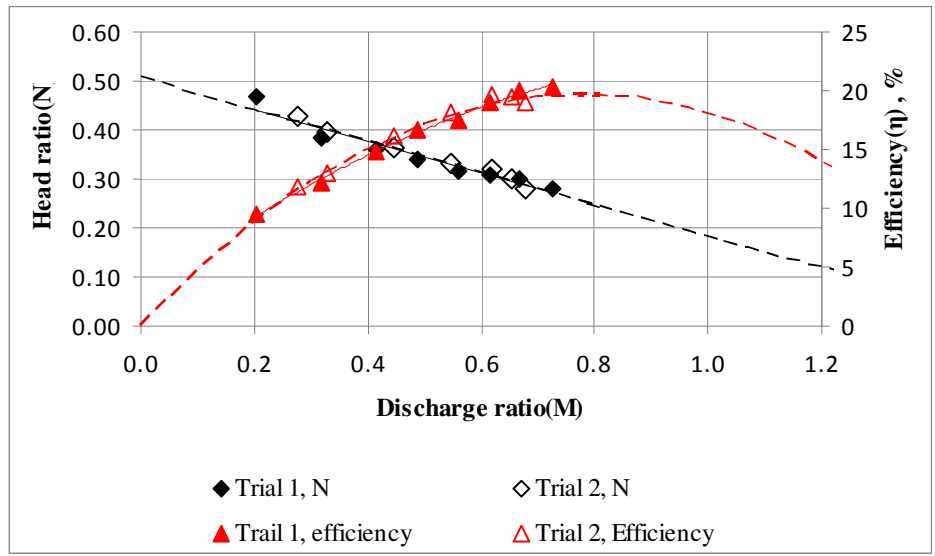

Figure8. Performance characteristics of jet pump with $\mathrm{R}=0.282 \& \mathrm{~S}=23 \mathrm{~mm}$

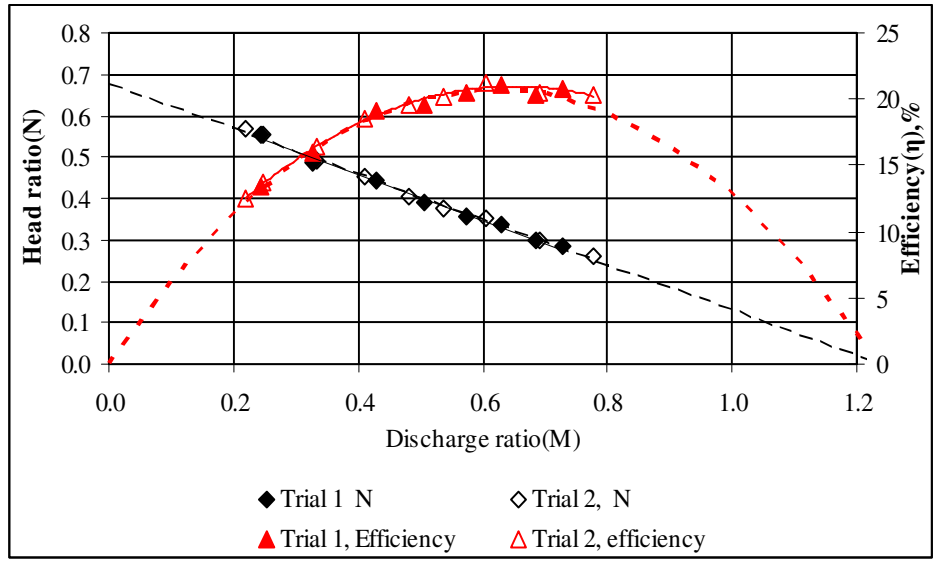

Figure9. Performance characteristics of jet pump with $\mathrm{R}=0.363 \& \mathrm{~S}=21.25 \mathrm{~mm}$ 
International Journal of Recent advances in Mechanical Engineering (IJMECH) Vol.3, No.4, November 2014

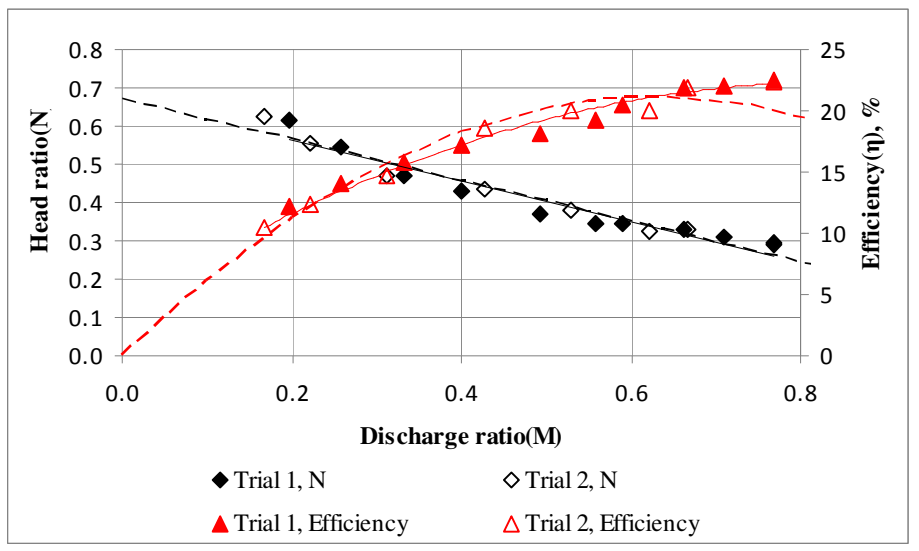

Figure10. Performance characteristics of jet pump with $\mathrm{R}=0.363 \& \mathrm{~S}=24.25 \mathrm{~mm}$

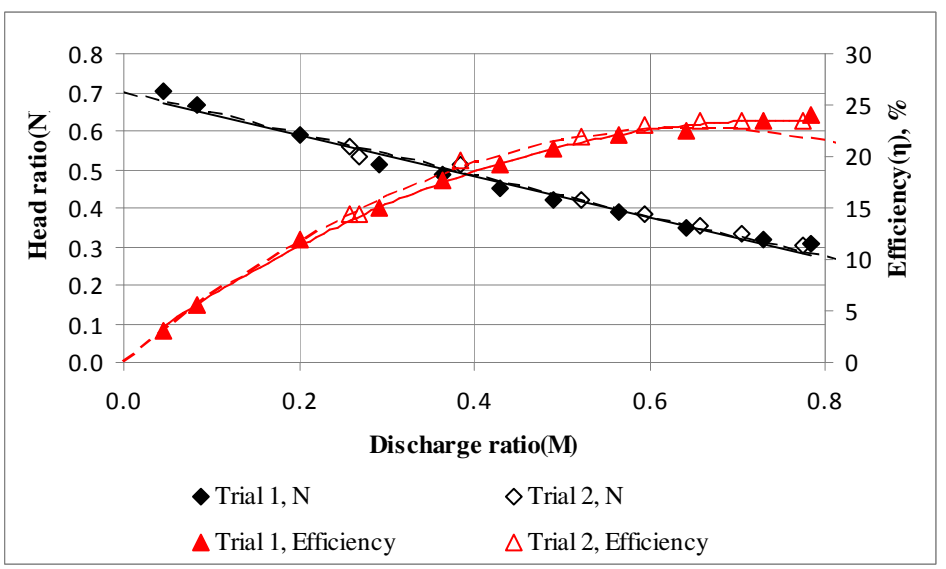

Figure11. Performance characteristics of jet pump with $\mathrm{R}=0.363 \& \mathrm{~S}=27.25 \mathrm{~mm}$

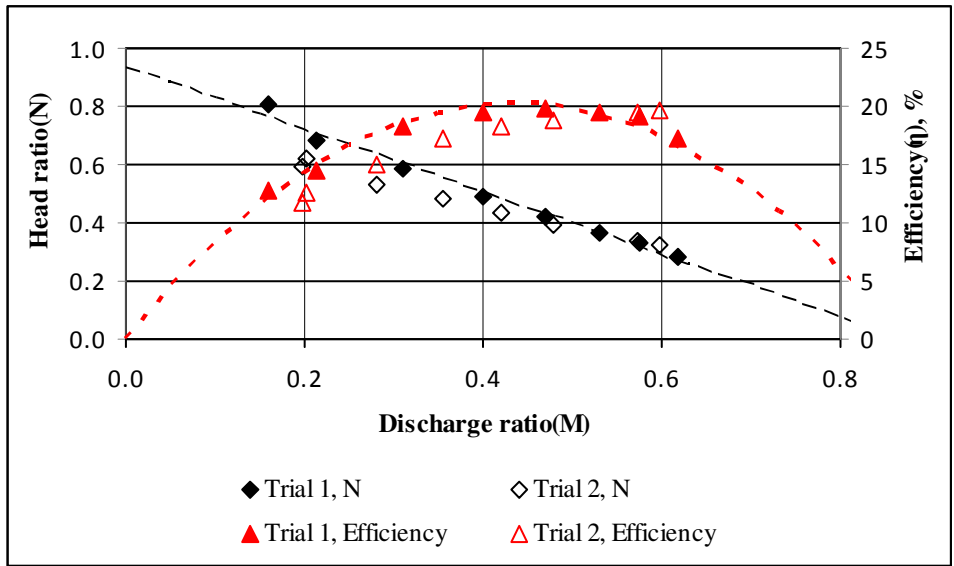

Figure12. Performance characteristics of jet pump with $\mathrm{R}=0.431 \& \mathrm{~S}=23.80 \mathrm{~mm}$ 
International Journal of Recent advances in Mechanical Engineering (IJMECH) Vol.3, No.4, November 2014

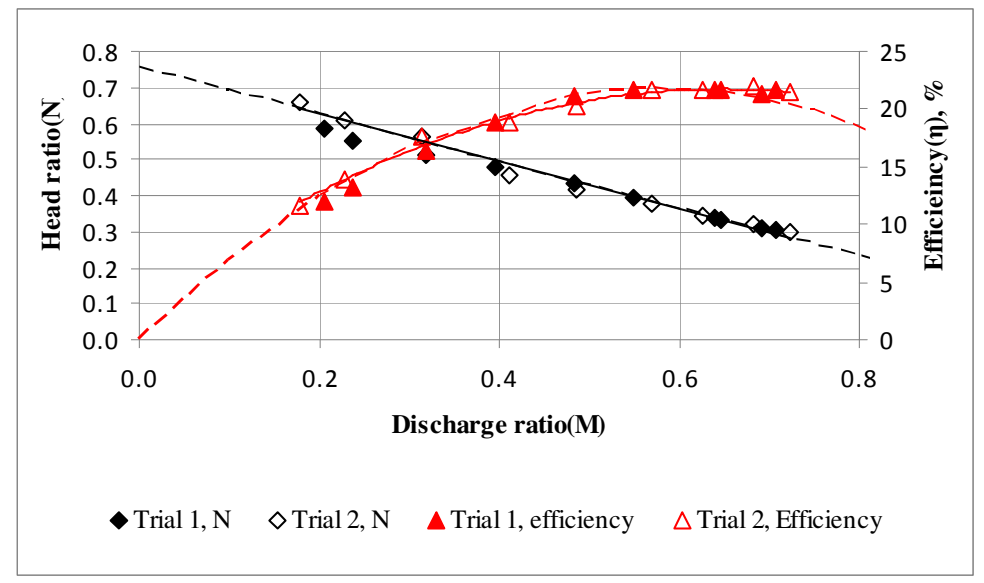

Figure13. Performance characteristics of jet pump with $\mathrm{R}=0.431 \& \mathrm{~S}=26.80 \mathrm{~mm}$

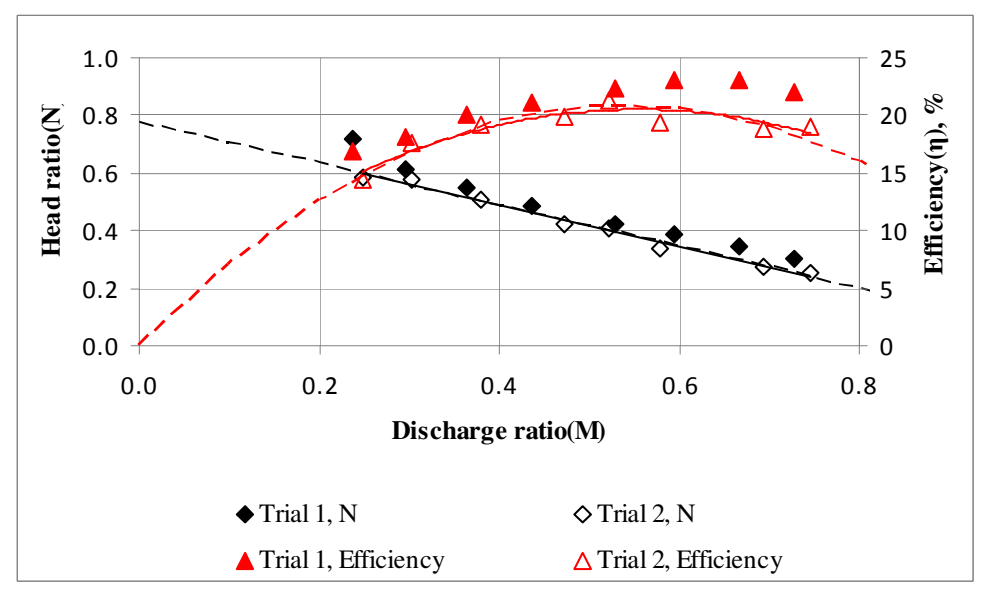

Figure14. Performance characteristics of jet pump with $\mathrm{R}=0.431 \& \mathrm{~S}=29.80 \mathrm{~mm}$

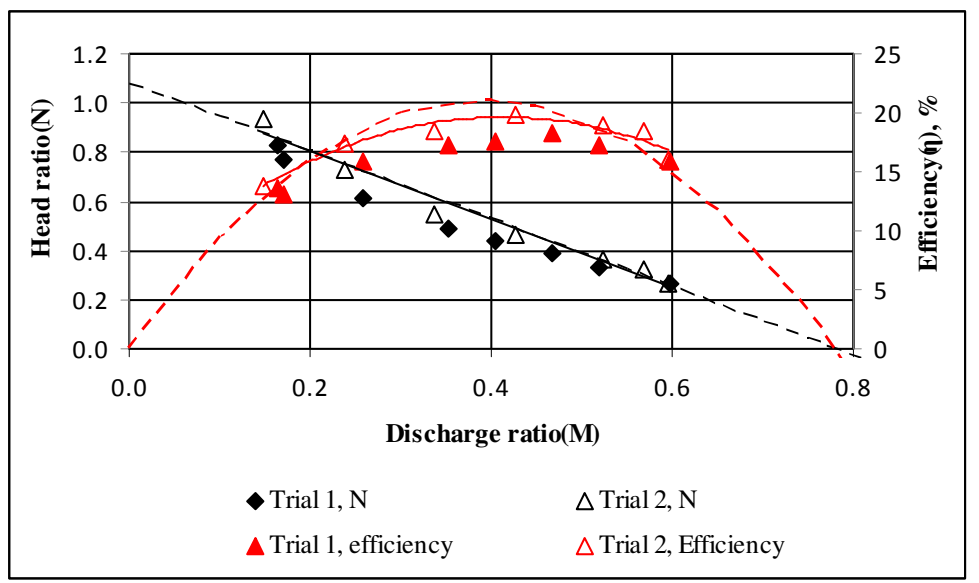

Figure15. Performance characteristics of jet pump with $R=0.502 \& S=25.50 \mathrm{~mm}$ 


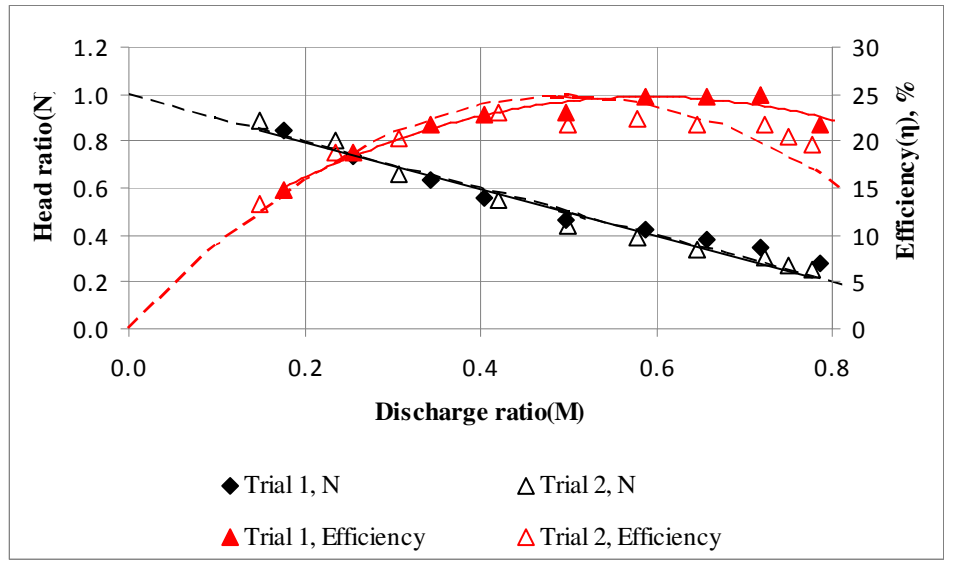

Figure16. Performance characteristics of jet pump with $\mathrm{R}=0.502 \& \mathrm{~S}=28.50 \mathrm{~mm}$

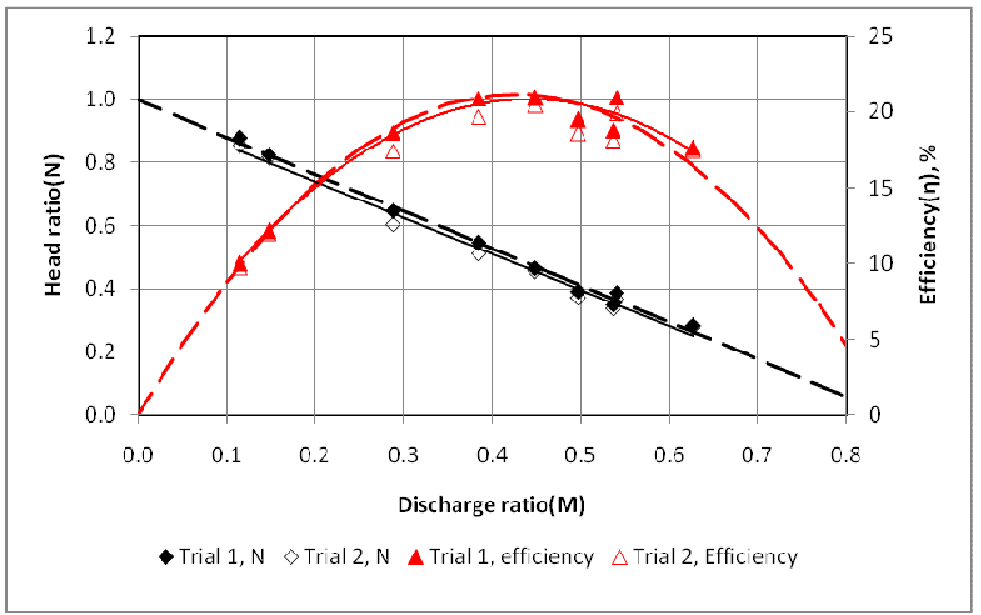

Figure17. Performance characteristics of jet pump with $\mathrm{R}=0.502 \& \mathrm{~S}=31.50 \mathrm{~mm}$

\section{CONCLUSION}

Fig.3 to 17 shows the consolidated results of the effect of change of $\mathrm{S}$ on the jet pump performance for various area ratios. A study of these figures indicate that as $\mathrm{S}$ increases, maximum efficiency decreases except for the case of $\mathrm{R}=0.20$. For $\mathrm{R}=0.20$ maximum efficiency increases as $\mathrm{S}$ increases. Here as spacing is increasing there is an increase in efficiency. It means that spacing will affect the performance of water to water jet pump.

\section{REFERENCES}

[1] Anil Kumar, N., 'Experimental Investigation of jet pump', M.Tech. Thesis, Hydroturbomachines Laboratory, IIT Madras, 2009.

[2] Bommaiah, B., 'Optimization of multihole nozzle jet pump', M.Tech. Thesis, Hydroturbomachines Laboratory, IIT Madras, 1977.

[3] Chakravarthi Devarla, K., 'Experimental Analysis on multihole nozzle Jet Pump', M.Tech. Thesis, Hydrotubomachines Laboratory, IITMadras, 2005

[4] Cunningham, R.G., Hansen, A. G. and Na, T.Y., 'Jet pump cavitation,' Trans. ASME., J1.Basic Engg., Sept.1970, pp.483-494. 
[5] Deenadayalan, C.R., 'Extending the operating range of multi-hole nozzle jet pump', M.Tech. Thesis, Hydroturbomachines Laboratory, IIT Madras, 2006.

[6] Gopichand, S., 'Experimental investigation on the performance of a multihole nozzle jet pump with various nozzle configurations', M.Tech. Thesis, Hydroturbomachines Laboratory, IIT Madras. 1979.

[7] Gosline, J.E. and M.P.O'Brien., ' The Water Jet pump' , University of California Publications in Engineering, Vol.3, 1934, pp.167-190

[8] Jagadeshwar, K, 'Experimental studies on multihole nozzle Jet Pump', M.Tech. Thesis, Hydrotubomachines Laboratory, IIT Madras, 2011.

[9] Kumaraswamy, S., 'Optimizing the performance of jet centrifugal pump combination', M.S. Thesis, Hydroturbomachines Laboratory, IIT Madras, 1974.

[10] Muller, N.G.H: 'Water Jet Pump', Journal of the Hydraulics Division, Proc. ASCE, Vol. 90, No. HY3, 1964, pp 83-113.

[11] Nilavalagan, S., 'Studies on the mixing characteristics of flow in a jet pump', Ph.D. thesis, Hydroturbomachines Laboratory, IIT Madras, 1985.

[12] Prasad babu. Y., 'Performance studies on a jet pump with multiple nozzles under cavitating and noncavitating conditions', M..Tech . Thesis, Hydrotubomachines Laboratory, IIT Madras, 2000.

[13] Ramakrishna Pai 'Optimized the mixing tube length on the basis of best efficiency for three area ratios at constant nozzle set back.', M.tech thesis Hydroturbomachines Laboratory, IIT Madras, 1986

[14] Ramesh Bapu, A.R., 'Design fabrication and erection of test facility for water to water jet pump', M.Tech thesis, Hydroturbomachines Laboratory, IIT Madras, 1981.

[15] Reddy, Y.R. and Subir Kar, 'Theory and Performance of Water Jet Pump' Proc. ASCE, Jl. Hyd. Div., Vol. 94, Sept. 1968, pp.1261-1281.

[16] Stepanoff, A.J., 'Centrifugal and axial flow pumps', 2nd Edition John Wiley, New York, 1957.

[17] Sudevan, K.K., 'Investigation on the mixing characteristics of a multihole nozzle water jet pump', M.Tech thesis, Hydroturbomachines Laboratory, IIT Madras, 1978. 